\title{
Socio-demographic correlates of postpartum psychological distress among apparently healthy mothers in two tertiary hospitals in Enugu, South-East Nigeria
}

\author{
Paul Odinka ${ }^{1}$, Jaclyn Odinka ${ }^{2}$, Mark Ezeme ${ }^{3}$, Appolos Ndukuba ${ }^{1}, K_{\text {Kennedy }}$ \\ Amadi $^{1}$, Rosemary Muomah ${ }^{1}$, Stanley Nwoha ${ }^{4}$, Ujunwa Nduanya ${ }^{5}$
}

1. Department of Psychological Medicine, University of Nigeria Enugu Campus.

2. Social Sciences Unit, School of General Studies, University of Nigeria Nsukka.

3. Department of Psychiatry, ESUT Teaching Hospital (Parklane) Enugu.

4. Department of Medicine, Nnamdi Azikiwe University Teaching Hospital, Nnewi.

5. Department of Psychological Medicine, University of Nigeria Teaching Hospital, Ituku-Ozalla, Enugu.

\begin{abstract}
Background: Postpartum depression and anxiety could cause poor mother-infant relationship that could impair infant growth and cognitive development. Psychiatric assessment has not been part of periodic evaluations in postnatal clinics. Some apparently well, but high-risk mothers continue to live with psychological distress, without treatment to relieve their burden.

Objectives: The study assessed the prevalence of postpartum anxiety and depression, their co-morbidity, and socio-demographic predictors, within 6 - 14 weeks postpartum among nursing mothers in two tertiary hospitals in Enugu, South-East Nigeria.

Methods: A cross-sectional study that was carried out at the postnatal and children's welfare clinics of two tertiary hospitals in Enugu, South-East Nigeria. Hospital Anxiety and Depression Scale, Social Support Scale and Socio-demographic Questionnaire were used for the study. Correlations and multiple regressions were used to test for associations and risk factors.

Results: Occurrence rate for anxiety and depression were $30.1 \%$ and $33.3 \%$ respectively with a co-morbidity rate of $22 \%$. Low social support and multigravida predicted risk factors for postpartum psychological distress, while a higher number of children alive predicted a decrease in the risk for postpartum psychological distress.

Conclusion: The study supports service planning and the development of strategies to reliably identify women at high-risk, for effective treatment.

Keywords: Postpartum Psychological Distress, Socio-demographic, Correlates, Apparently Healthy, Mothers, South-East Nigeria.

DOI: https://dx.doi.org/10.4314/ahs.v19i3.27

Cite as: Odinka P, Odinka J, Eqeme M, Ndukuba A, Amadi K, Muomah R, Nwoha S, Nduanya U. Socio-demographic correlates of postpartum psychological distress among apparently healthy mothers in two tertiary hospitals in Enugu, South-East Nigeria. Afri Health Sci. 2019;19(3): 2515-2525. bttps:// dx.doi.org/10.4314/ahs.v19i3.27
\end{abstract}

\section{Introduction}

Childbirth apart from being a major life event, ${ }^{1}$ can be associated with feelings of excitement, anticipation, and joy in most cultures. ${ }^{2}$ It also marks a period of change

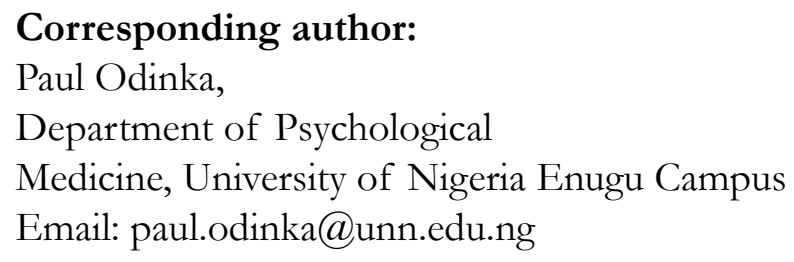

and adaptation that can result in emotional crisis, ${ }^{3}$ as the nursing mother tries to meet the needs of her baby, the family, adjusting to the changes in her sleep pattern, and to recover from the process and changes associated with delivery. ${ }^{4}$ These developmental and transitional challenges are frequently more stressful in bringing about more marked changes to roles, relationships, lifestyles, and family routine than any other single life event. ${ }^{3}$ The new challenges may combine with, or exacerbate existing stress that can lead to psychological distress. ${ }^{5}$

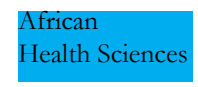

(C) 2019 Odinka et al. Licensee African Health Sciences. This is an Open Access article distributed under the terms of the Creative commons Attribution License (https://creativecommons.org/licenses/BY/4.0), which permits unrestricted use, distribution, and reproduction in any medium, provided the original work is properly cited. 
Psychological distress is mostly defined as a state of emotional suffering characterised by symptoms of depression and anxiety. ${ }^{6}$ It could be viewed as an emotional disturbance that may impact on the social functioning and dayto-day living of individuals, ${ }^{7}$ Postpartum psychological distress affects the health of the mother and her newborn, as well as her relationship within the household. The disturbances of mother-infant relationship, have been implicated in poor infant growth and cognitive development, ${ }^{8}$ poorer adherence to recommended immunisation schedules, ${ }^{9}$ and heightened the risk of insecure attachment and child behavioural problems. ${ }^{10,11}$

Postpartum depression (PPD) can develop at any point within the first year of postpartum, with a peak of incidence in the first four months following birth. ${ }^{12,13}$ PPD and Postpartum anxiety (PPA) affect approximately $35.4 \%$ and $15 \%$ of mothers respectively in Western societies, ${ }^{14,15}$ while a range of $2 \%$ to $13 \%$ was reported for co-morbidity. ${ }^{16,17}$ A prevalence of $23 \%$ to $31 \%$ was reported for PPD in Enugu, ${ }^{18,19}$ while 38\% and 10\% was reported for PPD and PPA respectively in South-West, Nigeria. ${ }^{20}$

In the Western societies, high parity is associated with increased risk to PPD and PPA $;^{21}$ however, Reck et al., (2008), ${ }^{16}$ observed no differences between the number of children and the risk to PPA and PPD. In Igbo culture, where marriage is patrilineal, one would expect a different outcome, as the position of a wife in her husband's family remains shaky and unpredictable until she begets children, especially a male, who will in the future inherit the land to keep the family name. ${ }^{22}$ Children are seen as the effective vindication of womanhood. ${ }^{22}$

The causes of postpartum psychological distress could be grouped into biological, social, and psychological factors, and these factors usually contribute to postpartum psychological distress in different proportions, ${ }^{23}$ depending on vulnerabilities or predispositions. Some socio-demographic factors such as low socioeconomic status, low educational attainment, low social or partner support, ${ }^{24} \mathrm{fe}-$ male gender, being single, ${ }^{25,26}$ long duration of marriage, ${ }^{27}$ and older age, ${ }^{16,25,28}$ have been associated with postpartum psychological distress. However, some previous studies had also reported that educational attainment, employment status, and area of residence did not correlate with postpartum psychological distress. ${ }^{12,29}$
While low family income and lack of emotional support are probably risk factors, ${ }^{30}$ higher education, having employment, and receiving postpartum care have been identified as protective factors. ${ }^{16,31}$ Social support may have a more substantial role in the aetiology of postpartum psychological distress than poverty-related issues. ${ }^{26,32}$ Nursing mothers with strong social support would have a lower probability of developing postpartum psychological distress compared to those with weak social support ${ }^{33}$ since they can readily turn to family and friends for support. ${ }^{32}$ And this is similar to "Omugwo" in Igbo culture. "Omugwo" is an Igbo cultural practice, in which the mother of the nursing mother, or her delegate, comes to stay with her in the early postpartum period. She takes care of the nursing mother, the baby, and help in the household chores, as well as teaching the nursing mother about baby-care.

The burden of psychological distress may be more in low and middle-income countries (LMIC) when compared with high resource countries. ${ }^{31}$ Despite available evidence suggesting that women may be at higher risk for postpartum anxiety (PPA), compared to postpartum depression (PPD), 34 and in some cases, with symptoms of depression and anxiety often co-occurring in postpartum psychological distress, barely adequate attention has focused on PPA. ${ }^{10}$

There is a shortage of literature on the prevalence of PPD and PPA, and their socio-demographic correlates in Nigeria, with a few attempts focused on the mothers residing in South-West Nigeria; occupied predominantly by the Yoruba, one of the three major ethnic groups in Nigeria. ${ }^{20,35}$ The ethnic and cultural differences may affect patterns of causation, presentations and the interpretations of psychological distress, ${ }^{36,37}$ hence a need for this study. This study aimed to investigate the occurrence rate of PPD and PPA, and their socio-demographic correlates in apparently healthy mothers in two tertiary hospitals in Enugu.

\section{Methods \\ Study setting}

The study was a cross-sectional study that was carried out in two tertiary hospitals in Enugu, Enugu State, SouthEast Nigeria. Both hospitals provide medical services to residents of Enugu state, and also receive referrals from all the five South-Eastern states and beyond. Enugu State 
has a population of 3.3 million people of whom $95 \%$ are Igbo. Enugu, apart from being the capital of Enugu State, is also a quasi-regional capital. The South-East is one of the six geopolitical zones in Nigeria. People of Igbo ethnic group, one of the three largest and most influential ethnic groups in Nigeria, primarily inhabit it. The Igbo people in Nigeria, who are predominantly Christians, constitute $18 \%$ of the total population of 170 million. ${ }^{38}$

\section{Ethical approval}

Approval for the study wasobtained from the Research Ethics Committee of the College of Medicine, University of Nigeria, Ituku-Ozalla Campus, Enugu. A written informed consent was sought and obtained from mothers before the study instruments were administered.

\section{Inclusion/Exclusion Criteria}

All the women, between the ages of 18 and above, whose babies were delivered from the gestational age of 36 weeks to term, were included in the study. Also, all women with conditions that might decrease the reliability of the assessment of PPA and PPD, such as obstetric factors, any severe medical illness, a history of psychiatric disorders, and recent traumatic life events, were excluded from the study to reduce confounding factors.

\section{Participants and sampling method}

All the nursing mothers who came for follow-ups and immunisation for children, at the postnatal clinics and Children's welfare clinics of the two hospitals, between November and December 2015 formed the sampling frame. A sample size of 303 participants was taken as adequate based on a prevalence of $23 \%, 18$ using Cochran's sample size formula for proportions. ${ }^{39}$ The assessment was done from 6th to $14^{\text {th }}$ weeks postpartum (the period from the 2 nd to the $4^{\text {th }}$ round of immunisation in Nigeria), since the highest prevalence has been observed within this time. $^{13}$

With the help of the outpatients' attendance list, randomisation table was used to select a total of 334 women for preliminary interviews to confirm the inclusion/ exclusion criteria. Eleven women withdrew or did not give their consent for the study, or had poorly completed questionnaires, while 14 mothers were excluded based on the inclusion/exclusion criteria. The mothers were first given a complete description of the study by one of the researchers before they completed the questionnaires.

\section{Instruments}

\section{Socio-demographic questionnaire}

Socio-demographic Questionnaire was used to collect socio-demographic data such as age, educational attainment, area of residence, ethnicity, religion, marital status, number of pregnancy, number of deliveries, number of children alive, occupations and employment status, and duration of the marriage.

\section{Hospital anxiety and depression Scale (HADS)}

HADS is a screening tool, designed as a brief self-report measure. ${ }^{40}$ It was designed to minimise the symptoms that might be ascribed to somatic disorders such as dizziness, insomnia, and fatigue while being able to detect individuals at higher risk for depression and anxiety. ${ }^{41}$ hence, the instrument could be used in a non-psychiatric setting. ${ }^{40}$ It has some positive qualities, including brevity and easiness of use, excellent reliability, and validity as well as efficiency in screening and case-finding. ${ }^{42}$ It consists of seven items each for depression and anxiety. Scores are rated on a four-point Likert Scale ranging from 0 to 3, with 21 as the highest score. A cut-off point of 11 and above in either or both of the anxiety and depressive subscales indicates depression and anxiety disorder based on the DSM-IV and ICD-10 diagnostic criteria. HADS has been validated in many countries including Nigeria. ${ }^{43}$

\section{The Oslo 3-item Social Support Scale (OSS-3)}

The Oslo 3-item Social Support Scale (OSS-3) was developed in 1996 by Dalgard. ${ }^{44,45}$ It includes the following questions: How many people that you are close to can you count on if you have a big personal problem? How much interest do people show in what you do? And How easy is it to get practical help from neighbours? The total score is calculated based on responses to all three questions. The overall score is calculated by adding up the raw scores for each item. The sum of the raw scores has a range from 3-14. A score ranging between 3 and 8 is classified as poor support, a score between 9 and 11 as intermediate support, and a score between 12 and 14 as strong support. ${ }^{45}$

The scale was included in a set of recommended common instruments in the EUROHIS project.46 OSS-3 has been validated in many countries, and Nigeria is one of them. ${ }^{47}$ 


\section{Data analysis}

The raw data were keyed into Epidata software version 3.1 (The EpiData Association, Odense, Denmark) for storage, and was later transported to Statistical Package for the Social Sciences (SPSS) version 20.0 (IBM, USA) for analysis. Frequency distribution of the socio-demographic characteristics of the nursing mothers, PPD and PPA were ascertained. Since all the continuous variables, as assessed by Shapiro-Wilk test of normality, did not have a Gaussian distribution,Spearman's correlations were performed to test the correlations between socio-demo- graphic data of the nursing mothers, and the PPD and PPA respectively. A multiple linear regression analysis was conducted to determine the socio-demographic predictors of PPD and PPA. All statistical tests were two-sided and were performed at a significant level of 0.05 .

\section{Results}

The age range of mothers was 20 - 46 years; mean, and S.D. was $29.65 \pm 4.87$. Mothers within the age range of $25-34$ years constituted $73.8 \%$ (228) of the respondents (See Table 1).

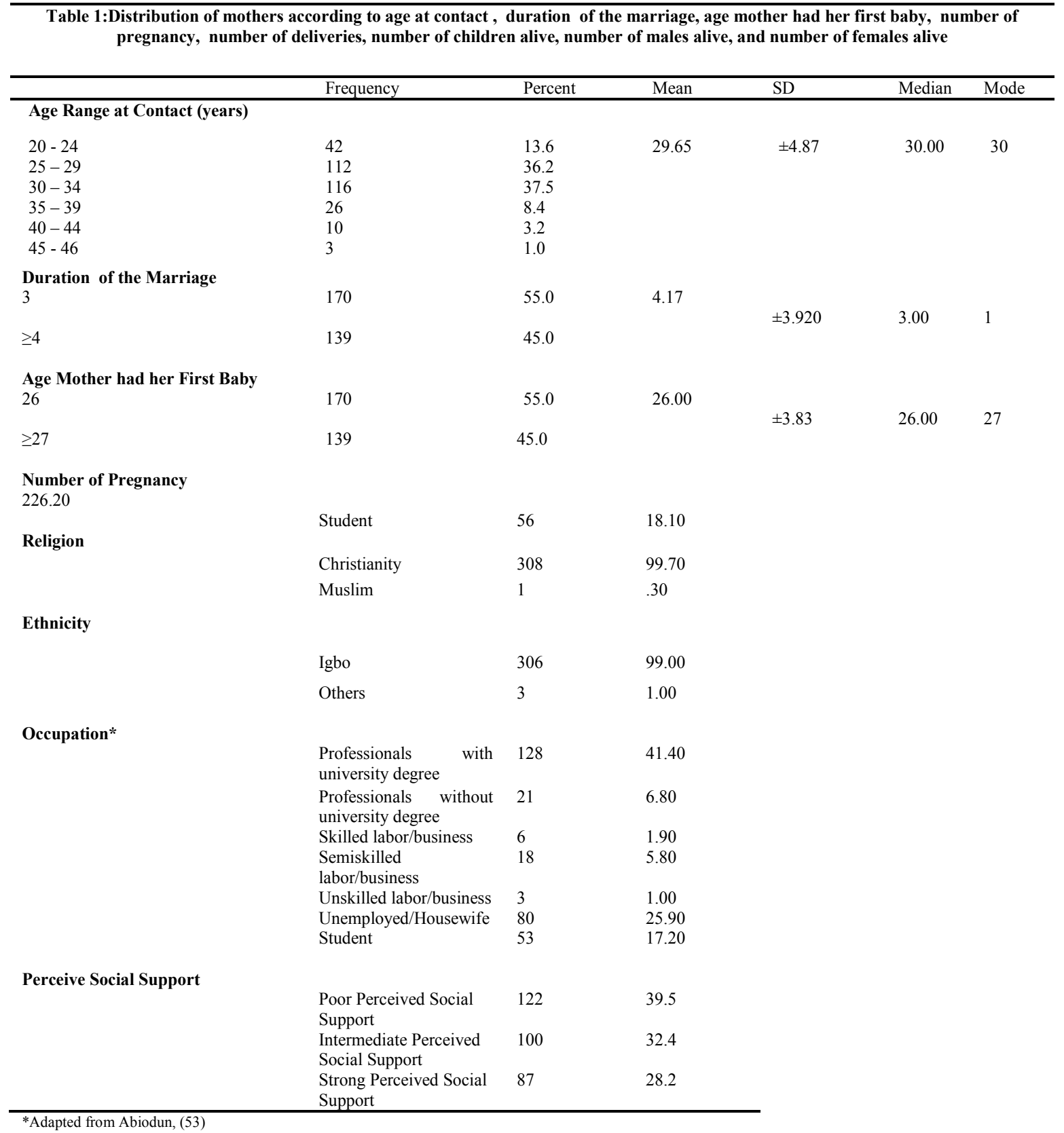


As shown in Table 2, most of the respondents were grad- tion with $1.6 \%$ of them dropping out of secondary school uates with either a university degree or a diploma (74.1\%), (second six years in school). The number of mothers that and all the respondents went beyond the primary educa- had PPD was 103 (33.3\%), while 93 (30.1\%) had PPA, with a co-morbidity rate of $22 \%$.

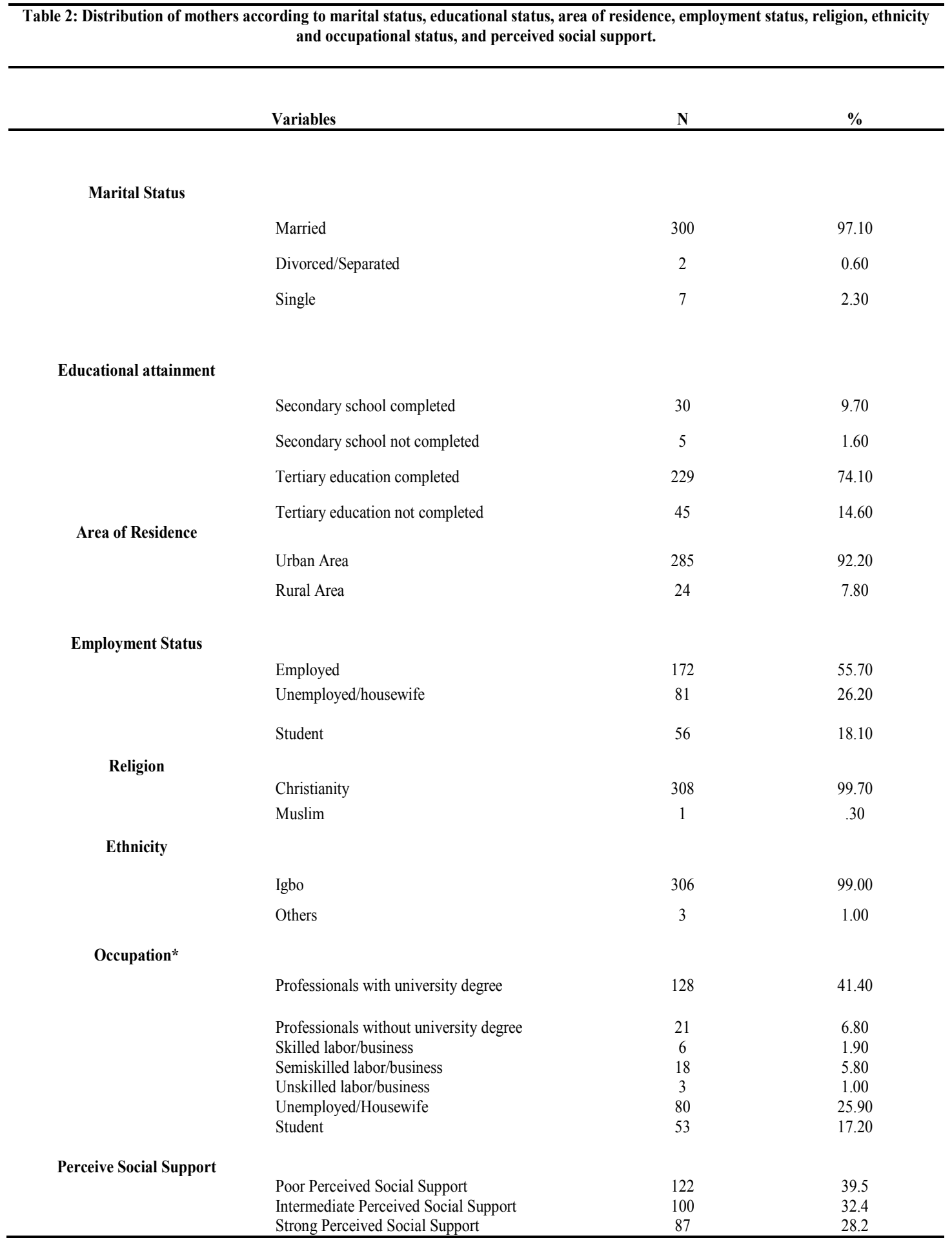

*Adapted from Abiodun, (53) 
There was a moderate negative correlation between the total score on OSS-3 and the overall score on HADS, (subscales for anxiety), $\mathrm{rs}=-0.400, \mathrm{p}<0.05$; where $\mathrm{r}$ are the degrees of freedom, obtained from the "Sig. (2-tailed)" row (See Table 3). There was a moderate negative correlation between the total score on OSS-3 and the overall score on HADS, (subscales for depression), rs $=-0.415, \mathrm{p}<0.05$; where $\mathrm{r}$ are the degrees of freedom, obtained from the "Sig. (2-tailed)" row (See Table 3).

Table 3: Correlations between postpartum anxiety, depression and socio-demographic factors

\section{Postpartum Anxiety}

\begin{tabular}{|c|c|c|c|c|c|c|c|}
\hline $\begin{array}{l}\text { Postpartum } \\
\text { Anxiety }\end{array}$ & $\begin{array}{l}\text { Mother's } \\
\text { Age }\end{array}$ & $\begin{array}{l}\text { Duration } \\
\text { of } \\
\text { Marriage }\end{array}$ & $\begin{array}{l}\text { Number of } \\
\text { Pregnancies }\end{array}$ & $\begin{array}{l}\text { Number of } \\
\text { Deliveries }\end{array}$ & $\begin{array}{l}\text { Children } \\
\text { Alive }\end{array}$ & $\begin{array}{l}\text { Marital } \\
\text { Status }\end{array}$ & $\begin{array}{l}\text { Social } \\
\text { Support }\end{array}$ \\
\hline
\end{tabular}

\begin{tabular}{|c|c|c|c|c|c|c|c|c|}
\hline \multicolumn{9}{|l|}{$\begin{array}{l}\text { Postpartum } \\
\text { Anxiety }\end{array}$} \\
\hline Mother's Age & .080 & & & & & & & \\
\hline $\begin{array}{l}\text { Duration of } \\
\text { Marriage }\end{array}$ & .098 & $.593^{* *}$ & & & & & & \\
\hline $\begin{array}{l}\text { Number } \\
\text { Pregnancies }\end{array}$ & $.171^{* *}$ & $.558^{* *}$ & $.880^{* *}$ & & & & & \\
\hline $\begin{array}{l}\text { Number } \quad \text { Of } \\
\text { Deliveries }\end{array}$ & $.126^{*}$ & $.509^{* *}$ & $.889^{* *}$ & $.927^{* *}$ & & & & \\
\hline $\begin{array}{l}\text { Number of } \\
\text { Children Alive }\end{array}$ & $.114^{*}$ & $.503^{* *}$ & $.885^{* *}$ & $.917^{* *}$ & $.988^{* *}$ & & & \\
\hline Marital Status & $.179^{* *}$ & $-.147^{* *}$ & $-.159^{* *}$ & -.103 & -.087 & -.089 & & \\
\hline Social Support & $-.400^{* *}$ & $-.262^{* *}$ & $-.303^{* *}$ & $-.387^{* *}$ & $-.352^{* *}$ & $-.353^{* *}$ & $-.179^{* *}$ & \\
\hline \multicolumn{9}{|c|}{ Note: $*$ = Correlation is significant at the $\mathbf{p}<.05$ level (2-tailed); $* *=$ Correlation is significant at the $\mathbf{p}<.01$ level (2-tailed). } \\
\hline \multicolumn{9}{|c|}{ Postpartum Depression } \\
\hline & $\begin{array}{l}\text { Postpartum } \\
\text { Depression }\end{array}$ & $\begin{array}{l}\text { Mother's } \\
\text { Age }\end{array}$ & $\begin{array}{l}\text { Duration } \\
\text { of } \\
\text { Marriage }\end{array}$ & $\begin{array}{l}\text { Number of } \\
\text { Pregnancies }\end{array}$ & $\begin{array}{l}\text { Number of } \\
\text { Deliveries }\end{array}$ & $\begin{array}{l}\text { Children } \\
\text { Alive }\end{array}$ & $\begin{array}{l}\text { Marital } \\
\text { Status }\end{array}$ & $\begin{array}{l}\text { Social } \\
\text { Support }\end{array}$ \\
\hline \multicolumn{9}{|l|}{$\begin{array}{l}\text { Postpartum } \\
\text { Depression }\end{array}$} \\
\hline Mother's Age & $.129^{*}$ & & & & & & & \\
\hline $\begin{array}{l}\text { Duration of } \\
\text { Marriage }\end{array}$ & $.152^{* *}$ & $.593 * *$ & & & & & & \\
\hline $\begin{array}{l}\text { Number } \\
\text { Pregnancies }\end{array}$ & $.189 * *$ & $.558 * *$ & $880^{* *}$ & & & & & \\
\hline $\begin{array}{l}\text { Number } \\
\text { Deliveries }\end{array}$ & $.146^{*}$ & $.509^{* *}$ & $.889^{* *}$ & $.927 * *$ & & & & \\
\hline $\begin{array}{l}\text { Number of } \\
\text { Children Alive }\end{array}$ & $.148^{* *}$ & $.503^{* *}$ & $.885^{* *}$ & $.917 * *$ & $.988^{* *}$ & & & \\
\hline Marital Status & .064 & $-.147 * *$ & $-.159 * *$ & -.103 & -.087 & -.089 & & \\
\hline Social Support & $-.415^{* *}$ & $-.262 * *$ & $-.303 * *$ & $-.387 * *$ & $-.352^{* *}$ & $-.353 * *$ & $-.179 * *$ & \\
\hline
\end{tabular}


A multiple regression was run to predict the total value of the scores of HADS, (for anxiety and depression subscales respectively), from the total value of the scores of marital status, number of pregnancies, number of children alive and OSS-3 (anxiety subscales) on one hand, and mother's age, duration of marriage, number of pregnancies, number of children alive and OSS-3 (depression subscales) on the other hand.

There was linearity as assessed by partial regression plots and a plot of studentized residuals against the predicted values for the two subscales. There was independence of residuals, as assessed by a Durbin-Watson statistic of 2.10. There was homoscedasticity, as assessed by visual inspection of a plot of studentized residuals versus unstandardized predicted values. There was no evidence of multicollinearity, as assessed by tolerance values greater than 0.1. There were no studentized deleted residuals greater than \pm 3 standard deviations, no leverage values greater than 0.2 , and values for Cook's distance above 1. The assumption of normality was met, as assessed by Q-Q Plot.
For the anxiety subscales, it was found that the total number of pregnancies and OSS-3scores explained a significant amount of the variance in the value of total HADS (subscales for anxiety) scores. And the multiple regression models statistically significantly predicted postpartum depression, $(\mathrm{F}(4,304)=15.307, \mathrm{p}<.05, \mathrm{R} 2=.17$, $\mathrm{R} 2$ Adjusted $=.16)$. Two of the four independent variables, number of pregnancies and OSS-3, added statistically significantly to the prediction, $(p<0.05)$. Regression coefficients and standard errors can be found in Table 4 . For the depression subscales, it was found that the total number of pregnancies, number of children alive and OSS-3 scores explained a significant amount of the variance in the value of total HADS (subscales for depression) scores. And the multiple regression models significantly predicted postpartum depression, $(\mathrm{F}(5,303)=$ 13.752, $\mathrm{p}<.05, \mathrm{R} 2=.19$, R2 Adjusted $=.17)$. Three of the five independent variables, number of pregnancies, number of children alive and OSS-3, added statistically significantly to the prediction, $(\mathrm{p}<0.05)$. Regression coefficients and standard errors can be found in Table 4.

\section{Table 4: Multiple regression analysis for variables predicting postpartum anxiety and depression from socio-demographic factors}

\begin{tabular}{|c|c|c|c|c|c|c|c|c|c|c|c|}
\hline \multicolumn{12}{|c|}{ Postpartum Anxiety Coefficients } \\
\hline \multirow[t]{2}{*}{ Model } & \multicolumn{4}{|c|}{$\begin{array}{l}\text { Unstandardized } \\
\text { Coefficients } \\
\end{array}$} & \multirow{2}{*}{$\begin{array}{l}\text { Beta } \\
\beta\end{array}$} & \multirow[t]{2}{*}{$\mathrm{t}$} & \multirow[t]{2}{*}{$P^{*}$} & \multicolumn{2}{|c|}{$\begin{array}{l}95.0 \% \text { Confidence } \\
\text { Interval for B }\end{array}$} & \multicolumn{2}{|c|}{ Collinearity Statistics } \\
\hline & \multicolumn{2}{|c|}{$\mathrm{B}$} & \multicolumn{2}{|l|}{$\begin{array}{l}\text { Std. } \\
\text { Error }\end{array}$} & & & & $\begin{array}{l}\text { Lower } \\
\text { Bound }\end{array}$ & $\begin{array}{l}\text { Upper } \\
\text { Bound }\end{array}$ & Tolerance & VIF \\
\hline Intercept (Constant) & & & 1.605 & & & 6.822 & .000 & 7.790 & 14.105 & & \\
\hline Number of pregnancies & & & .273 & & .271 & 2.331 & .020 & .099 & 1.174 & .203 & 4.922 \\
\hline Number of children alive & & & .327 & & -.207 & -1.828 & .069 & -1.240 & .046 & .214 & 4.679 \\
\hline Marital status & & & .974 & & .091 & 1.682 & .094 & -.278 & 3.556 & .931 & 1.074 \\
\hline Social Support & & & .086 & & -.326 & -5.596 & .000 & -.652 & -.313 & .806 & 1.241 \\
\hline \multicolumn{12}{|c|}{ Postpartum depression coefficients } \\
\hline \multirow[t]{2}{*}{ Model } & \multicolumn{3}{|c|}{$\begin{array}{l}\text { Unstandardized } \\
\text { Coefficients }\end{array}$} & Beta & $\mathrm{t}$ & $P^{*}$ & \multicolumn{3}{|c|}{$\begin{array}{l}95.0 \% \\
\text { Interval for B }\end{array}$} & \multicolumn{2}{|c|}{ Collinearity Statistics } \\
\hline & $\mathrm{B}$ & $\begin{array}{l}\text { Std. } \\
\text { Error }\end{array}$ & & $\beta$ & & & $\begin{array}{l}\text { Lower } \\
\text { Bound }\end{array}$ & $\begin{array}{l}\text { Upp } \\
\text { Bou }\end{array}$ & & Tolerance & VIF \\
\hline Intercept (Constant) & 14.584 & 1.778 & & & 8.204 & .000 & 11.085 & 18.0 & & & \\
\hline mother's age & -.019 & .055 & & -.024 & -.349 & .728 & -.126 & .088 & & .571 & 1.750 \\
\hline Duration of marriage & .103 & .088 & & .105 & 1.171 & .242 & -.070 & 277 & & .336 & 2.972 \\
\hline Number of pregnancies & .590 & .279 & & .254 & 2.110 & .036 & .040 & 1.14 & & .186 & 5.369 \\
\hline $\begin{array}{l}\text { Number of children } \\
\text { alive }\end{array}$ & -.919 & .340 & & -.322 & -2.702 & .007 & -1.588 & -.25 & & .189 & 5.285 \\
\hline Social Support & -.576 & .082 & & -.394 & -7.014 & .000 & -.737 & -.41 & & .852 & 1.173 \\
\hline
\end{tabular}




\section{Discussion}

The study investigated the occurrence rate of PPD and PPA, and their socio-demographic correlates in apparently healthy mothers in two tertiary hospitals in Enugu, South-East Nigeria. The study observed that 33.3\%, of the mothers, ostensibly had depression (PPD); while $30.0 \%$ of them had anxiety (PPA), Previous studies had also reported high prevalence rates, $35.4 \%$ in women in postpartum period using standardised screening instrument ${ }^{14}$ and $17.0 \%$ in women in the postpartum period (4-12 weeks after childbirth). ${ }^{48}$ In Enugu, South-East Nigeria, Chinawa et al. (2016), ${ }^{18}$ and Ukaegbe et al., (2012), ${ }^{19}$ reported a prevalence of $23 \%-31 \%$, while in south-western Nigeria, Fatoye et al., (2006), reported that between $5 \%$ and $38 \%$ of women suffer from postpartum depression, and approximately 10\% develop an anxiety disorder after delivery. We found that $22.0 \%$ of the nursing mothers had co-morbid anxiety and depressive symptomatology during the first 14 weeks postpartum. Previous studies had reported prevalence ranging from $2 \%$ to $13 \%$ of co-morbidity rate for PPD and PPA in the first year. ${ }^{16,17}$

The study observed that nursing mothers with low social support had a higher probability of developing anxiety and depression than those with optimal social support, and this has been reported in previous studies. ${ }^{33,49}$ Nursing mothers are more likely to turn to family and friends for support in the first postpartum month, ${ }^{50}$ and this is similar to "Omugwo" in Igbo culture.

We observed that the increase in the mother's age, and the duration of marriage correlated mildly with PPD, Prior studies had observed that increases in age were among other risk factors for depression. ${ }^{16,28}$ However, McCoy et al., (2006), ${ }^{12}$ and Chaya et al., (2002), ${ }^{29}$ reported no association between postpartum depression and age. ${ }^{29}$ Also, mother's age and the duration of marriage failed to predict increased risk for PPD. The relationship between marriage duration and postpartum depression may be due to stress that is usually associated with the delays in achieving pregnancy. ${ }^{27}$ Though the marital status showed a weak positive correlation with PPA, it failed to predict PPA in regression analysis. Also, marital status showed no correlation with PPD, but previous studies had observed that single mothers were at higher risk for depression. ${ }^{26}$ Being multigravid predicted an increased risk of PPA and PPD. Prior studies had suggested that despite a woman's history of successful experience with pregnancy, previous adverse childbirth experiences influence her emotional state, ${ }^{51,52}$ which increases the risk for PPA..$^{53}$

2522
An increase in the number of children alive predicted a decreased risk to PPA and PPD; this is in contrast to studies in the Western societies, where multiparity increased the risk to PPA and PPD. ${ }^{21}$ The difference could be due to Igbo culture placing a high premium on women begetting children. ${ }^{22}$, Reck et al., (2008), ${ }^{16}$ observed no differences between the number of children and the risk to PPA and PPD. Also, educational attainment, employment status, and area of residence did not correlate with PPA and PPD, and this was in line with previous studies. ${ }^{12,29}$

\section{Limitations}

The limitations of the study include the cross-sectional design that would not permit any causal relationships to be ascertained. The study included only nursing mothers, who visited the indexed clinics of the study centres; therefore, the study sample was selective rather than representative, and cannot be generalised to the entire population of South-East Nigeria.

\section{Conclusion}

The study observed that symptoms of anxiety and depression were very high (30.1\% and 33.3\% respectively) within the first 14 weeks among postpartum women, with a co-morbidity of $22 \%$. Low social support and multigravida, predicted postpartum psychological distress, while the number of children alive was able to predict the decrease in the risk for postpartum psychological distress. Most nursing mothers with psychological distress are likely to suffer because of the low detection rate, which makes it most unlikely for them to benefit from the right intervention. There is a need to develop strategies for early detection of women with high-risk of PPD and PPA for the appropriate interventions because of the attendant consequences on the general well-being of the child, the mother, and the family.

\section{Conflict of interest}

None to declare.

\section{References}

1. Holmes TH, Rahe RH. The social readjustment rating scale. Journal of Psychosomatic Research. 1967; 31;11(2):2138.

2. Murphey C, Carter P, Price LR, Champion JD, Nichols F. Psychological Distress in Healthy Low-Risk First-Time Mothers during the Postpartum Period: An Exploratory Study. Nursing Research and Practice. 2017; 16;2017.

3. Raynor M. Psychology for midwives: pregnancy, child-

African Health Sciences Vol 19 Issue 3, September, 2019 
birth and puerperium. $1^{\text {st }}$ ed. UK: McGraw-Hill Education, 2010.

4. Hilli R. Evidence-based public health practices for screening for postpartum depression. 2011. Retrieved on 28/11/16 from http://corescholarlibrarieswrightedu/ $\mathrm{mph} / 48$

5. Jevitt CM, Groer MW, Crist NF, Gonzalez L, Wagner VD. Postpartum stressors: A content analysis. Issues in Mental Health Nursing. 2012; 27;33(5):309-18.

6. Mirowsky J. and Ross CE. "Selecting outcomes for thesociology of mental health: Issues of measurement and dimensionality." Journal of Health and Social Behavior. 2002; 43:152-170.

7. Wheaton B. The twain meet: distress, disorder and the continuing conundrum of categories (comment on Horwitz). Health. 2007;11(3):303-19.

8. Petzoldt J, Wittchen HU, Einsle F, Martini J. Maternal anxiety versus depressive disorders: specific relations to infants' crying, feeding and sleeping problems. Child: Care, Health and Development. 2016; 1;42(2):231-45.

9. Rahman A, Iqbal Z, Bunn J, Lovel H, Harrington R. Impact of maternal depression on infant nutritional status and illness: a cohort study. Archives of General Psychiatry. 2004; 1;61(9):946-52.

10. Glasheen C, Richardson GA, Fabio A. A systematic review of the effects of postnatal maternal anxiety on children. Archives of Women's Mental Health. 2010; 1;13(1):61-74.

11. Cooper PJ, Murray L.Fortnightly review: Postnatal depression. BMJ: British Medical Journal. 1998; 20;316(7148):1884.

12. McCoy SJ, Beal JM, Shipman SB, Payton ME, Watson $\mathrm{GH}$. Risk factors for postpartum depression: a retrospective investigation at 4-weeks postnatal and a review of the literature. Journal of the American Osteopathic Association. 2006; 1;106(4):193.

13. Miller RL, Pallant JF, Negri LM. Anxiety and stress in the postpartum: is there more to postnatal distress than depression?. BMC Psychiatry. 2006; 24;6(1):12.

14. Evins GG, Theofrastous JP, Galvin SL. Postpartum depression: a comparison of screening and routine clinical evaluation. American Journal of Obstetrics and Gynecology. 2000; 31;182(5):1080-2.

15. Sawyer A, Ayers S, Smith H. Pre-and postnatal psychological wellbeing in Africa: a systematic review. Journal of Affective Disorders. 2010; 30;123(1):17-29.
16. Reck C, Struben K, Backenstrass M, Stefenelli U, Reinig K, Fuchs T, et al. Prevalence, onset and comorbidity of postpartum anxiety and depressive disorders. Acta Psychiatrica Scandinavica. 2008; 1;118(6):459-68.

17. Austin MP, Hadzi-Pavlovic D, Priest SR, Reilly N, Wilhelm K, Saint K, et al. Depressive and anxiety disorders in the postpartum period: how prevalent are they and can we improve their detection?. Archives of Women's Mental Health. 2010; 1;13(5):395-401.

18. Chinawa JM, Odetunde OI, Ndu IK, Ezugwu EC, Aniwada EC, Chinawa AT, et al. Postpartum depression among mothers as seen in hospitals in Enugu, South-East Nigeria: an undocumented issue. Pan African Medical Journal. 2016;23(1).

19. Ukaegbe CI, Iteke OC, Bakare MO, Agbata AT. Postpartum depression among Igbo women in an urban mission hospital, south east Nigeria. EMJ: Ebonyi Medical Journal. 2012;11(1\&2):29-36.

20. Fatoye FO, Oladimeji BY, Adeyemi AB. Difficult delivery and some selected factors as predictors of early postpartum psychological symptoms among Nigerian women. Journal of Psychosomatic Research. 2006; 31;60(3):299-301.

21. Nielsen D, Videbech P, Hedegaard M, Dalby J, Secher NJ. Postpartum depression: identification of women at risk. BJOG: An International Journal of Obstetrics \& Gynaecology. 2000 Oct 1;107(10):1210-7.

22. Obi CA. Marriage among the Igbo of Nigeria. ATR Special Topics. 1970. Retrieved on 28/10/16 from http://nigeriamasterweb.com/igbomarriage.html.

23. Kendall-Tackett KA. Depression in new mothers: Causes, consequences and treatment alternatives. $3^{\text {rd }} \mathrm{ed}$. London: Routledge, 2016.

24. O'Hara MW. Postpartum depression: what we know. Journal of Clinical Ppsychology. 2009; 12;65(12):1258-69.

25. Krause N, Dowler D, Liang J, Gu S, Yatomi N, Chuang YL. Sex, marital status, and psychological distress in later life: A comparative analysis. Archives of Gerontology and Geriatrics. 1995; 1;21(2):127-46.

26. Wissart J, Parshad O, Kulkarni S. Prevalence of preand postpartum depression in Jamaican women. BMC Pregnancy and Childbirth. 2005; 8;5(1):15.

27. Soltani M, Shairi MR, Roshan R, Rahimi CR. The impact of emotionally focused therapy on emotional distress in infertile couples. International Journal of Fertility \& Sterility. 2014;7(4):337. 
28. Muraca GM, Joseph KS. The association between maternal age and depression. Journal of Obstetrics and Gynaecology Canada. 2014; 30;36(9):803-10.

29. Chaaya M, Campbell OM, El Kak F, Shaar D, Harb H, Kaddour A. Postpartum depression: prevalence and determinants in Lebanon. Archives of women's Mental Health. 2002; 1;5(2):65-72.

30. Ghubash R, Hamdi E, Bebbington P. The Dubai community psychiatric survey: I. Prevalence and socio-demographic correlates. Social psychiatry and psychiatric epidemiology. 1992; 1;27(2):53-61.

31. Fisher J, Mello MC, Patel V, Rahman A, Tran T, Holton S, Holmes W. Prevalence and determinants of common perinatal mental disorders in women in low-and lower-middle-income countries: a systematic review. Bulletin of the World Health Organization. 2012; 90(2):139-49.

32. Milgrom J, Martin PR, Negri LM. Treating postnatal depression: a psychological approach for health care practitioners. Chichester: Wiley; 1999.

33. Sanjana M, Jayashankar RK. Psychological Distress in Diabetes: A Critical Review. International Journal of Recent Scientific Research. 2013; 9:1381- 1384.

34. Ross LE, McLean LM, Psych C. Anxiety disorders during pregnancy and the postpartum period: a systematic review. Depression. 2006; 6(9):1-4.

35. Adewuya AO, Afolabi OT. The course of anxiety and depressive symptoms in Nigerian postpartum women. Archives of Women's Mental Health. 2005; 11;8(4):257-9. 36. Odinka PC, Ndukuba AC, Muomah RC, Amadi AU, Osika MU, Bakare MO, et al. The relative contributions of clinical and socio-cultural factors to treatment delay among patients with schizophrenia in south-east Nigeria. International Journal of Psychosocial Rehabilitation. 2015; 1;19(2):63-74.

37. Jegede AS. The Yoruba cultural construction of health and illness. Nordic Journal of African Studies. 2002; 11(3):322-35.

38. Central Intelligence Agency. Calculation from percentage and overall population count of Nigeria. In: CIA The World Factbook. Virginia, USA: Directorate of Intelligence, 2015.

39. Cochran WG. Sampling techniques. $3^{\text {rd }}$ ed. New York: Wiley, 1977.

40. Zigmond AS, Snaith RP. The hospital anxiety and depression scale. Acta Psychiatrica Scandinavica. 1983; 1;67(6):361-70.

41. Chan YF, Leung DY, FongDY, Leung CM, Lee AM. Psychometric evaluation of the Hospital Anxiety and Depression Scale in a large community sample of adolescents in Hong Kong. Quality of Life Research. 2010; 1;19(6):865-73.

42. Luckett T, Butow PN, King MT, Oguchi M, Heading $G$, Hackl NA, et al. A review and recommendations for optimal outcome measures of anxiety, depression and general distress in studies evaluating psychosocial interventions for English-speaking adults with heterogeneous cancer diagnoses. Supportive Care in Cancer. 2010 Oct 1;18(10):1241-62.

43. Abiodun OA. A validity study of the Hospital Anxiety and Depression Scale in general hospital units and a community sample in Nigeria. The British Journal of Psychiatry. 1994; 1;165(5):669-72.

44. Dalgard OS. Community health profile as tool for psychiatric prevention. Promotion of Mental Health. 1996; 5:681-95.

45. Bøen H, Dalgard OS, Bjertness E. The importance of social support in the associations between psychological distress and somatic health problems and socio-economic factors among older adults living at home: a cross sectional study. BMC Geriatrics. 2012; 8;12(1):27.

46. Nosikov A, Gudex C. . Development of a common instrument for mental health. EUROHIS: Developing common instruments for health surveys. 2003; 57:35.

47. Abiola T, Udofia O, Zakari M. Psychometric properties of the 3-item oslo social support scale among clinical students of Bayero University Kano, Nigeria. Malaysian Journal of Psychiatry. 2013; 12;22(2):32-41.

48. Mina S, Balhara YP, Verma R, Mathur S. Anxiety and Depression amongst the urban females of Delhi in Ante-partum and Post-partum period. Delhi Psychiatry Journal. 2012; 15(2):347-351

49. Taylor E. Postnatal depression: what can a health visitor do?. Journal of advanced nursing. 1989; 1;14(10):877-86. 50. Miligrom J, Martin PR, Negri LM. Treating postpartum depression: A psychological approach for health care practitioners. New York: John Willey and Sons Ltd, 1999 51. Côté-Arsenault D. The influence of perinatal loss on anxiety in multigravidas. Journal of Obstetric, Gynecologic, \& Neonatal Nursing. 2003; 1;32(5):623-9. 
52. Tsartsara E, Johnson MP. The impact of miscarriage on women's pregnancy-specific anxiety and feelings of prenatal maternal-fetal attachment during the course of a subsequent pregnancy: An exploratory follow-up study. Journal of Psychosomatic Obstetrics \& Gynecology. 2006; 1;27(3):173-82.
53. Farr SL, Dietz PM, O'Hara MW, Burley K, Ko JY. Postpartum anxiety and comorbid depression in a population-based sample of women. Journal of Women's Health. 2014; 1;23(2):120-8. 